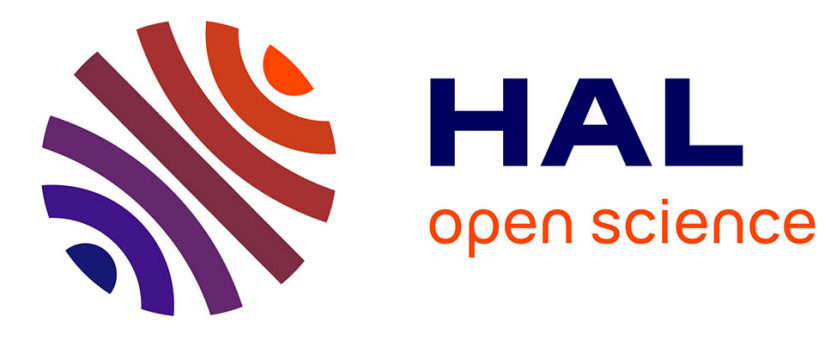

\title{
Synthesis and characterization of poly(ester amide amide)s of different alkylene chain lengths
}

Clément Girard, Manisha Gupta, Abdelaziz Lallam, Denis Anokhin, Polina

Bovsunovskaya, Azaliya Akhyamova, Alexey Melnikov, Alexey Piryazev, Alexander Rodygin, Andrey Rychkov, et al.

\section{To cite this version:}

Clément Girard, Manisha Gupta, Abdelaziz Lallam, Denis Anokhin, Polina Bovsunovskaya, et al.. Synthesis and characterization of poly(ester amide amide)s of different alkylene chain lengths. Polymer Bulletin, 2019, 76 (1), pp.495-509. 10.1007/s00289-018-2361-7 . hal-02415169

\author{
HAL Id: hal-02415169 \\ https://hal.science/hal-02415169
}

Submitted on 7 Jan 2021

HAL is a multi-disciplinary open access archive for the deposit and dissemination of scientific research documents, whether they are published or not. The documents may come from teaching and research institutions in France or abroad, or from public or private research centers.
L'archive ouverte pluridisciplinaire HAL, est destinée au dépôt et à la diffusion de documents scientifiques de niveau recherche, publiés ou non, émanant des établissements d'enseignement et de recherche français ou étrangers, des laboratoires publics ou privés. 


\title{
Synthesis and Characterization of Poly(ester amide amide)s of Different Alkylene Chain Lengths
}

\author{
GIRARD Clément ${ }^{11}$, GUPTA Manisha ${ }^{21 \dagger}$, LALLAM Abdelaziz ${ }^{1}$, ANOKHIN Denis V. ${ }^{3,4}$, BOVSUNOVSKAYA \\ Polina V. ${ }^{3,5}$, AKHYAMOVA Azaliya F. ${ }^{3,5}$, MELNIKOV Alexey P. ${ }^{3,5}$, PIRYAZEV Alexey A. ${ }^{3,5}$, RODYGIN \\ Alexander I. ${ }^{3,5}$, RYCHKOV Andrey A. ${ }^{3,5}$, GRAFSKAYA Kseniia N. ${ }^{3}$, SHABRATOVA Ekaterina D. ${ }^{3}$, ZHU \\ Xiaomin $^{2}$, MÖLLER Martin ${ }^{2}$, IVANOV Dimitri A. ${ }^{3,6}$
}

\begin{abstract}
In this work a series of aliphatic biodegradable poly(ester amide amide) polymers was synthesized by melt polycondensation of a tailor-made amide-containing monomer based on 1,4-diaminobutane and $\varepsilon$-caprolactone and different dicarboxylic acid methyl esters with even number of methylene groups. The synthesized polymers were characterized by ${ }^{1} \mathrm{H}$ NMR, FT-IR spectroscopy, GPC, SAXS and WAXS. DSC results show that the melting point is located at about $150^{\circ} \mathrm{C}$ for all polymers. X-ray scattering experiments in small and wide angles reveal formation of crystals with extended-chain conformation resulting in strict periodicity of electron density along the main chain. TGA data indicates the high thermal stability of polymers to temperatures above $350^{\circ} \mathrm{C}$, which are much above the melting point. The obtained characteristics of the newly synthesized PEAAs can open new perspectives for melt processing to fabricate films, highly oriented fibers and injection-molded parts with good thermal stability and mechanical performance.
\end{abstract}

\footnotetext{
${ }^{1}$ Laboratoire de Physique et Mécanique Textile, Université de Haute Alsace, 68093 Mulhouse, France

${ }^{2}$ DWI - Leibniz-Institute for Interactive Materials e.V. and Institute for Technical and Macromolecular Chemistry of RWTH Aachen University, Forckenbeckstraße 50, 52056 Aachen, Germany

${ }^{3}$ Moscow Institute of Physics and Technology (State University), Institutskiy per. 9, Dolgoprudny, 141700, Russia

${ }^{4}$ Institute for Problems of Chemical Physics RAS, Semenov Av. 1, Chernogolovka, Moscow Region, 142432, Russia

${ }^{5}$ Lomonosov Moscow State University, Faculty of Fundamental Physical and Chemical Engineering, GSP-1, 1-51 Leninskie Gory, Moscow, 119991, Russia

${ }^{6}$ Institut de Sciences des Matériaux de Mulhouse (CNRS UMR 7361), 15 rue Jean Starcky, B.P 2488, Mulhouse, 68057, France

' Authors contributed equally to the work

${ }^{\dagger}$ Deceased $1^{\text {st }}$ November 2017
}

Keywords poly(ester amide amide)s _ biodegradable polymers _ melt polycondensation _ Small-Angle X-ray Scattering _ Wide-Angle X-ray Scattering 


\section{Introduction}

Biodegradable polymers have emerged as a solution for the global environmental pollution problem caused by the non-degradable waste products.[1,2] Nowadays, they are increasingly used in different fields ranging from packaging to biomedical applications. Aliphatic polyesters such as poly(lactic acid), poly(glycolic acid) and their copolymers are typical examples of synthetic biodegradable polymers. However, they still have limited applications due to poor mechanical properties and insufficient processibility. On the other hand, aliphatic polyamides have good mechanical and thermal stability but are non-biodegradable. The desired combination of properties can be achieved by synthesis of poly(ester amide)s (PEAs) with either randomly distributed amide groups [3-14] or with well-defined amide blocks in the polymer chain [15-21]. The poly(ester amide)/polyamide copolymers of different microstructures i.e. random, alternating or segmented, can be prepared depending on the monomer nature and synthetic route.

Segmented PEAs containing both rigid amide and flexible ester blocks exhibit a microphase separated structure typical of thermoplastic elastomers.[22-28] Such polymers form homogeneous melts upon heating above the melting temperature of hard segments and thus can be easily melt-processed. During cooling, the microphase separation of the rigid amide and soft ester domains takes place. The crystalline lamellae of the rigid phase serve as a thermoreversible physical network within the elastic ester phase. Therefore, the properties of PEAs can be tuned in a wide range by varying the amide and ester contents.[22,23,29]

Several groups have synthesized aliphatic segmented PEAs having uniform amide blocks. Preformed bisamide-diols, oligoesters, bisamide-esters were copolymerized with diols and dimethyl adipates to obtain high molecular weight segmented PEAs.[18-21,30] The effect of hard-to-soft segments' ratio on the physical-chemical properties of PEAs was studied in detail. Thus, Lips and colleagues[22] synthesized high molecular weight segmented PEAs by melt polycondensation of preformed bisamide-diol based on 1,4-diaminobutane and $\varepsilon$-caprolactone with 1,4-butanediol and dimethyl adipate. The increase of hard segment content from 10 to $85 \mathrm{~mol} \%$ results in enhancement of the mechanical modulus from 70 to $524 \mathrm{MPa}$ and the stress at break from 8 to $28 \mathrm{MPa}$. For all the synthesized polymers, a single glass transition was observed, which increases with the increase in hard segment content indicating the presence of a homogeneous amorphous phase. In addition, two endothermic peaks at low and high temperatures were attributed to melting of the crystals formed by single ester amide (EA) sequences and by two or more EA sequences, respectively. The low-temperature transition was independent from polymer composition while the high-temperature transition peak was found to move to higher temperatures with the increase of the hard-segment content.

Garg and co-authors[23] have synthesized segmented PEAs consisting of single amide groups, two adjacent amide groups or three adjacent amide groups by melt polycondensation of amide-containing monomers, butylene adipate and 1,4-butanediol, and the preformed monomers were $\alpha, \omega$-diol, $\alpha, \omega$-aminoalcohol and $\alpha, \omega$-diamine with an in-built amide group, respectively. Varying amount of these preformed monomers in the feed leads to different contents of amide groups in the PEAs and thus result in different physical-chemical properties of the synthesized PEAs. Among all these materials the copolymers containing two adjacent amide groups exhibited an interesting crystalline structure, which is formed by both ester and amide groups. In this work, we focus on the homopolymers from $\alpha, \omega$-amino alcohols and dicarboxylic acid methyl esters, which are two monomers for the synthesis of polymers with two adjacent amide groups, and address their crystalline structures and physical-chemical properties. In these polymers the molar ratio of ester to amide groups is 1:2, so they are called poly(ester amide amide)s (PEEAs), and the number of adjacent amide groups can be 2 and 4. In principle, a microphase separated structure cannot be expected for PEEAs, however, the presence of ester groups should impart the biodegradability.

\section{Materials}

$\varepsilon$-Caprolactone (97\%), 1,4-diaminobutane (99\%), and dimethyl adipate (DMA) $(98 \%)$ were purchased from Aldrich. Dimethyl suberate (DMSUB) (99\%), and dimethyl sebacate (DMSEB) (97\%) were obtained from Alfa Aesar. Titanium IV isopropoxide was purchased from ABCR. 2-Propanol (absolute) was purchased from Fluka, 2,2,2trifluoroethanol was purchased from Sigma Aldrich. The solvents such as tetrahydrofuran and methanol were purchased from VWR. All the chemicals were used without additional purification.

\section{Synthesis}




\section{Synthesis of monomer}

Tailor-made monomer $\alpha, \omega$-aminoalcohol $\left(\mathrm{HO}\left(\mathrm{CH}_{2}\right)_{5} \mathrm{CONH}\left(\mathrm{CH}_{2}\right)_{4} \mathrm{NH}_{2}\right.$, AA) was prepared according to the procedure described in literature.[31] A solution of $\varepsilon$-caprolactone $(100.0 \mathrm{~g}, 0.88 \mathrm{~mol})$ in THF $(80 \mathrm{~mL})$ was dropped to a solution of 1,4-diaminobutane $(271.04 \mathrm{~g}, 3.08 \mathrm{~mol})$ in THF $(260 \mathrm{~mL})$. This reaction mixture was stirred for $20 \mathrm{~h}$ at room temperature. Afterwards, the excess of 1,4- diaminobutane and THF were removed in high vacuum $\left(10^{-2} \mathrm{mbar}\right)$ by slow heating to $60^{\circ} \mathrm{C}$. The product was then dissolved in methanol and precipitated in cold diethyl ether. The white product was filtered and dried in vacuum with $80 \%$ yield $\left(\mathrm{mp} 75^{\circ} \mathrm{C}\right)$.

\section{Synthesis of poly(ester amide amide)s}

The PEAAs were synthesized by a two-step melt polycondensation according to Scheme 1. Equimolar ratio of tailormade monomer AA and dicarboxylic esters of different alkylene chain length (e.g., dimethyl adipate, dimethyl suberate and dimethyl sebacate) were added to a glass reactor, which was equipped with a mechanical stirrer. Ti (IV) isopropoxide $(5 \mathrm{mg} / \mathrm{g}$ of dicarboxylic acid ester) in isopropanol $(1 \% \mathrm{w} / \mathrm{w})$ was then added to the reactor under inert atmosphere. The reaction mixture was then slowly heated to $170^{\circ} \mathrm{C}$ under a pressure of 100 mbar. Under stirring the heating was continued for another $5 \mathrm{~h}$. Further reaction was performed by heating the reaction mixture slowly to $180^{\circ} \mathrm{C}$ and by decreasing the pressure to $1 \mathrm{mbar}$. At the final temperature, the reaction was carried out for $4 \mathrm{~h}$ in a high vacuum of $10^{-2}$ mbar. At the end, the resulting melt was retrieved from the reactor, dissolved in 2,2,2-trifluoroethanol and precipitated in diethyl ether. The procedure was repeated 3 times. The final product dried at $50{ }^{\circ} \mathrm{C}$ in a vacuum oven for $8 \mathrm{~h}$.

\section{Characterization techniques}

Nuclear magnetic resonance (NMR) spectroscopy: ${ }^{1} \mathrm{H}$ NMR spectra were obtained on a Bruker DPX 300 operating at $300 \mathrm{MHz}$. Deuterated trifluoroacetic acid was used as solvent with TMS as internal standard.

Elemental analysis: Chemical composition of synthesized PEAA was evaluated by elementary analysis of carbon, hydrogen and nitrogen using Carlo Erba MOD 1106 instrument.

Fourier transform infrared spectroscopy (FT-IR): FT-IR spectra were collected using Thermo Nicolet Model Nexus 470 spectrophotometer equipped with a DTGS detector from 100 signal-averaged scans with $8 \mathrm{~cm}^{-1}$ resolution. The samples were in the form of a thin polymer film of ca. $25 \mathrm{~mm} \times 10 \mathrm{~mm}$ placed on $\mathrm{KBr}$ disc. The data was collected in the range of $500-4000 \mathrm{~cm}^{-1}$.

Gel permeation chromatography (GPC): GPC measurements were performed on a Waters 1515 Isocratic HPLC pump, a Viscotek 250 model refractive index detector, a Waters 2707 auto-sampler, a PSS PFG guard column followed by 2 PFG-linear-XL $(7 \mu \mathrm{m}, 8 * 300 \mathrm{~mm})$ columns in series at $40{ }^{\circ} \mathrm{C}$. Hexafluoroisopropanol (HFIP, Biosolve) with potassium trifluoro acetate $(3 \mathrm{~g} / \mathrm{L})$ and toluene $(2.5 \mathrm{~mL} / \mathrm{L})$ was used as eluent at a flow rate of $0.8 \mathrm{~mL} / \mathrm{min}$. The molecular weights were calibrated with PMMA standards (Polymer Laboratories, $\mathrm{Mp}=580 \mathrm{Da}$ up to $\mathrm{Mp}=7.1 * 10^{6}$ $\mathrm{Da})$.

Themogravimetric analysis: A TG-209 (Netzsch) instrument was used to study the thermal stability of the synthesized polymers. To this purpose, $2-4 \mathrm{mg}$ of the sample was placed in a standard Netzsch aluminum pan and heated in nitrogen from $30^{\circ} \mathrm{C}$ to $700^{\circ} \mathrm{C}$ at a heating rate of $10^{\circ} \mathrm{C} / \mathrm{min}$.

Differential scanning calorimetry: DSC measurements were carried out on a DSC-204 (Netzsch, Germany). For the experiments, $5-8 \mathrm{mg}$ of sample was sealed in a standard Netzsch aluminum pan and were heated from $0{ }^{\circ} \mathrm{C}$ to $220^{\circ} \mathrm{C}$ at a heating rate of $10^{\circ} \mathrm{C} / \mathrm{min}$. The flow rate of nitrogen was $10 \mathrm{~cm}^{3} / \mathrm{min}$. The temperature of the phase transition was determined as the onset of the corresponding peak on the DSC curve.

SAXS/WAXS: Small- (SAXS) and wide-angle (WAXS) X-ray scattering data were measured on a XeuSS diffractometer (Xenocs) equipped with a GeniX3D $\left(\lambda=1.54 \AA\right.$ ) source providing a beam of ca. $300 \times 300 \mu \mathrm{m}^{2}$ in size. Two-dimensional SAXS patterns were recorded with a Pilatus 300k detector at the sample-to detector distance of $1324.44 \mathrm{~mm}$. Two-dimensional WAXS images were collected with a Rayonix LX170-HS detector positioned $91 \mathrm{~mm}$ away from the sample. The modulus of the scattering vector $\mathbf{s}(|\mathbf{s}|=2 \sin \Theta / \lambda$, where $\Theta$ is the Bragg angle and $\lambda$ - the wavelength) was calibrated using seven diffraction orders of silver behenate. 


\section{Results and discussions}

In this work, the polycondensation of $\alpha, \omega$-aminoalcohol AA with dicarboxylic acid methyl esters of different alkylene chain length (cf. Scheme 1) results in PEAAx with a theoretical ratio of ester to amide groups 1:2. The synthesized polymers are denoted as PEAA4, PEAA6 and PEAA8, where the digit indicates the number of the methylene groups in the dicarboxylic acid methyl ester.

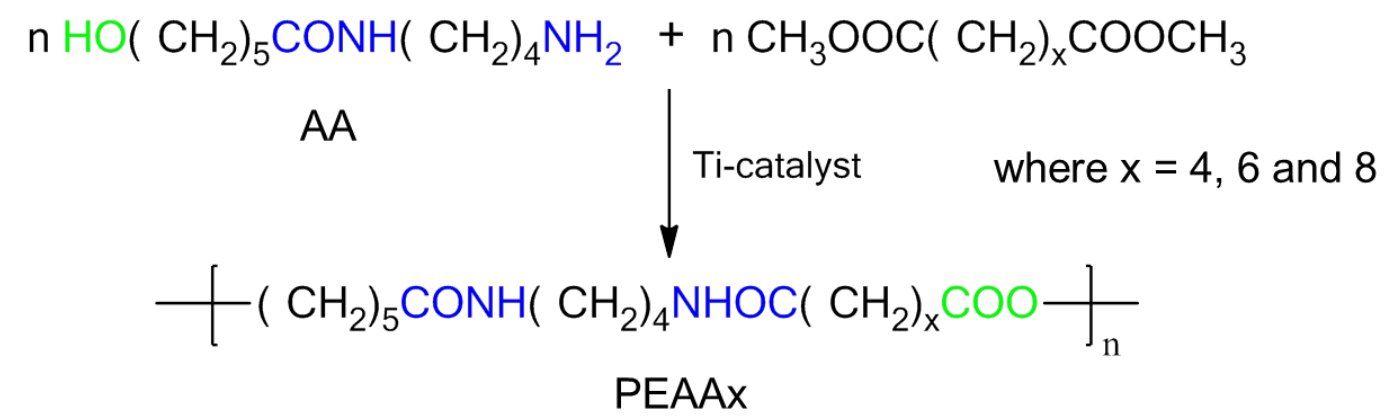

Scheme 1: Synthesis of PEAAx by melt polycondensation.

${ }^{1} \mathrm{H}$ NMR spectroscopy was used to determine the chemical composition of PEAA4, PEAA6 and PEAA8. The ratio of ester to amide groups in PEAAs $\left(X_{e / a}\right)$ was calculated from ${ }^{1} \mathrm{H}$ NMR spectra according to Eq (1):

$X_{e / a}=I_{e} / I_{a}$

where $I_{e}$ and $I_{a}$ stand for the integral intensities of protons at $\delta=4.1 \mathrm{ppm}$ and $\delta=3.4 \mathrm{ppm}$, which correspond to $\mathrm{CH}_{2}$ groups connected directly to oxygen and nitrogen atom, respectively. An example of a ${ }^{1} \mathrm{H}$ NMR spectrum of PEAAs is presented in Figure 1. The experimental values of $X_{e / a}$ in the PEEAs summarized in Table 1 are in good agreement with the theoretical values. A small deviation from the theoretical composition can be accounted for by removal of a small amount of dicarboxylic methyl esters by distillation during the precondensation step. The chemical composition was also confirmed by elemental analysis. The experimental contents of different elements coincide well with the theoretical ones ( $c f$. Table 1). According to GPC data, all synthesized polymers exhibit a monomodal molecular weight distribution and relatively high molecular weight ( $c f$. Table 2). The polydispersity index (PDI) is about 2, which is typical for polymers prepared via polycondensation. 


$$
\begin{gathered}
-\mathrm{CH}_{2}-\mathrm{CH}_{2}-\mathrm{CH}_{2}-\mathrm{CH}_{2}-\mathrm{CH}_{2}-\mathrm{CO}-\mathrm{NH}-\mathrm{CH}_{2}-\mathrm{CH}_{2}-\mathrm{CH}_{2}-\mathrm{CH}_{2}-\mathrm{NH}-\mathrm{CO} \\
\left.\qquad \mathrm{CH}_{2}-\mathrm{CH}_{2}-\mathrm{CH}_{2}-\mathrm{CH}_{2}-\mathrm{CH}_{2}-\mathrm{CH}_{2}-\mathrm{CH}_{2}-\mathrm{CH}_{2}-\mathrm{COO}\right]_{\mathrm{n}} \mathrm{Ie}
\end{gathered}
$$

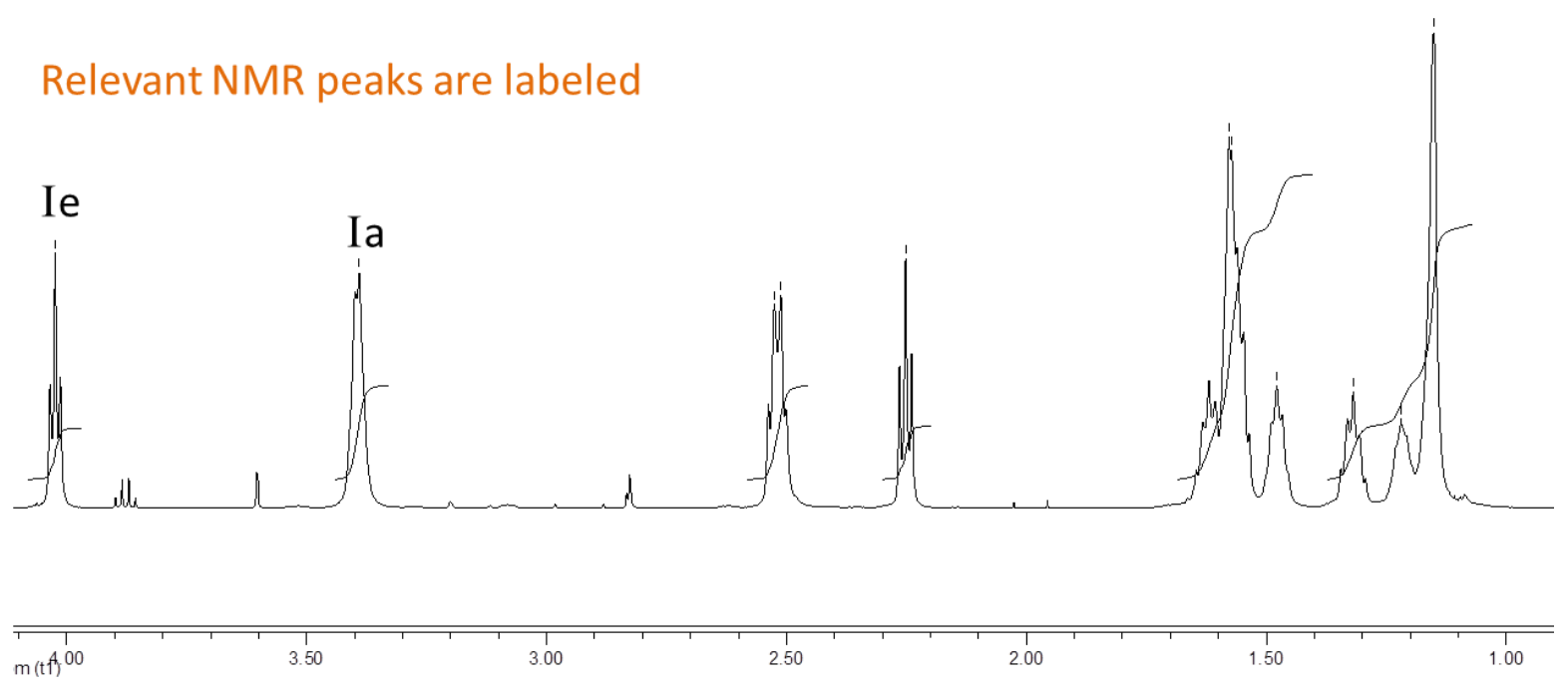

Figure 1: 1H NMR spectra of PEEAs exemplified for the case of PEAA8 in d-TFA.

Table 1: Chemical composition of PEAAs

\begin{tabular}{|c|c|c|c|c|c|c|c|c|c|}
\hline \multirow[t]{2}{*}{ Polymer } & \multirow[t]{2}{*}{ Monomer 1, g } & \multirow[t]{2}{*}{ Monomer 2, g } & \multirow[t]{2}{*}{$X_{e / a}$} & \multicolumn{3}{|c|}{ Theoretical } & \multicolumn{3}{|c|}{ Experimental } \\
\hline & & & & $\mathrm{C}, \%$ & $\mathrm{H}, \%$ & $\mathrm{~N}, \%$ & $\mathrm{C}, \%$ & $\mathrm{H}, \%$ & $\mathrm{~N}, \%$ \\
\hline PEAA4 & $\mathrm{AA}, 10$ & DMA, 8.71 & $1: 1.84$ & 61.54 & 8.97 & 8.97 & 61.03 & 8.85 & 8.60 \\
\hline PEAA6 & AA, 10 & DMSUB, 10.11 & $1: 1.88$ & 63.53 & 9.41 & 8.23 & 62.82 & 11.68 & 7.99 \\
\hline PEAA8 & $\mathrm{AA}, 10$ & DMSEB, 11.52 & $1: 1.84$ & 65.22 & 9.78 & 7.61 & 64.52 & 9.78 & 7.22 \\
\hline
\end{tabular}

Elemental composition

Table 2: Molecular weight and polydispersity of PEAAs

\begin{tabular}{llll}
\hline Polymer & $\mathbf{M}_{\mathbf{n}}(\mathbf{k D a})$ & $\mathbf{M}_{\mathbf{w}}(\mathbf{k D a})$ & PDI \\
\hline PEAA4 & 15.7 & 35.5 & 2.26 \\
PEAA6 & 34.9 & 50.7 & 1.45 \\
\hline
\end{tabular}




\begin{tabular}{llll}
\hline PEAA8 & 20.5 & 55.5 & 2.70 \\
\hline
\end{tabular}

The FTIR spectra of the synthesized polymers taken for the wavenumber regions of 3600-2700 and $1800-650 \mathrm{~cm}^{-1}$ are presented in Figure 2 (a) and 1 (b), respectively. All PEAAs show the characteristic IR peaks at $\sim 1732$ ( $v$ CO ester), $\sim 1635 \mathrm{~cm}^{-1}$ (amide I, ( $\vee \mathrm{CO}$ ) and $\sim 1541 \mathrm{~cm}^{-1}$ (amide II $\vee \mathrm{CN}+\mathrm{CO} v \mathrm{NH}$ bend), which reveal the presence of both ester and amide bonds in the polymer backbone. The IR spectra of the PEAAs also indicate the appearance of a strong Hbond peak at $\sim 3300 \mathrm{~cm}^{-1}$ ( $v$ NH H-bonded) with a shoulder at $\sim 3400 \mathrm{~cm}^{-1}(v \mathrm{OH} \mathrm{H}-$ bonded). Several weaker bands at $1474 \mathrm{~cm}^{-1}$ ( $\mathrm{NH}$ vicinal $\mathrm{CH}_{2}$ bend), $\sim 1420 \mathrm{~cm}^{-1}$ (CO vicinal $\mathrm{CH}_{2}$ bend), $\sim 1260 \mathrm{~cm}^{-1}$ (amide III), $\sim 693 \mathrm{~cm}^{-1}$ (amide V) and $\sim 585 \mathrm{~cm}^{-1}$ (amide VI) show the crystallization of amide rigid blocks.[32] In nylon 6 the most stable crystalline polymorphs are $\alpha$ and $\gamma$ phases. The main peaks of the synthesized PEAAs and the characteristic peaks of nylon 6 in $\alpha$ and $\gamma$ crystal phases are listed in Table 3. A more detailed analysis of the IR bands shows that the crystal structure of PEAA4 is a mixture of $\alpha$ and $\gamma$ modifications of Nylon-6, whereas in PEAA6 and PEAA8 only $\alpha$ crystalline phase was observed.

(a)

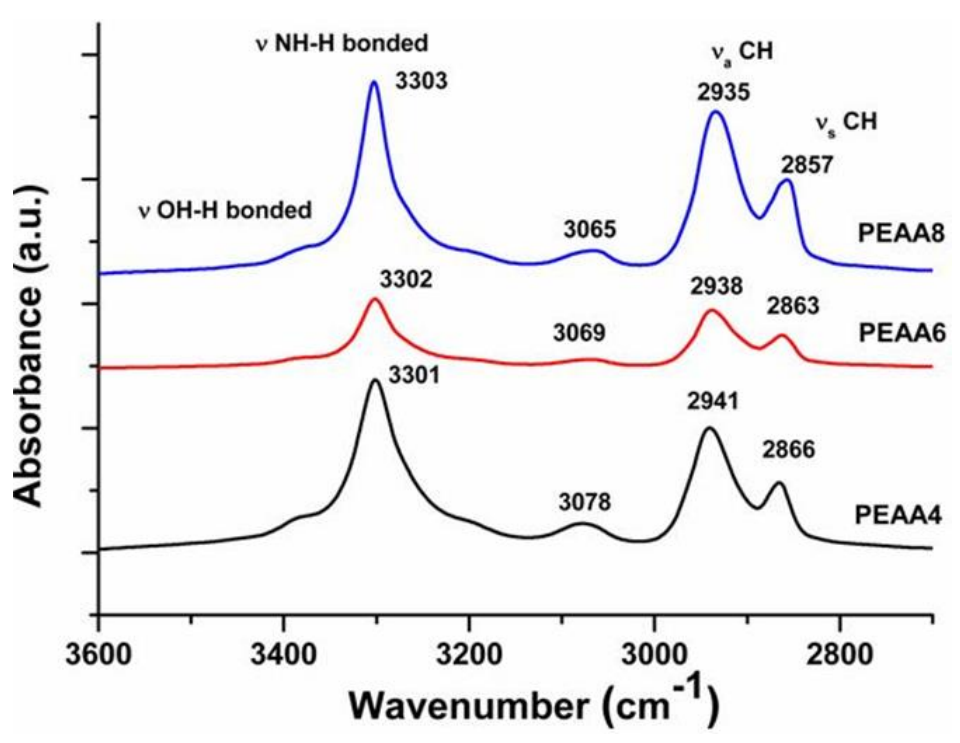

(b)

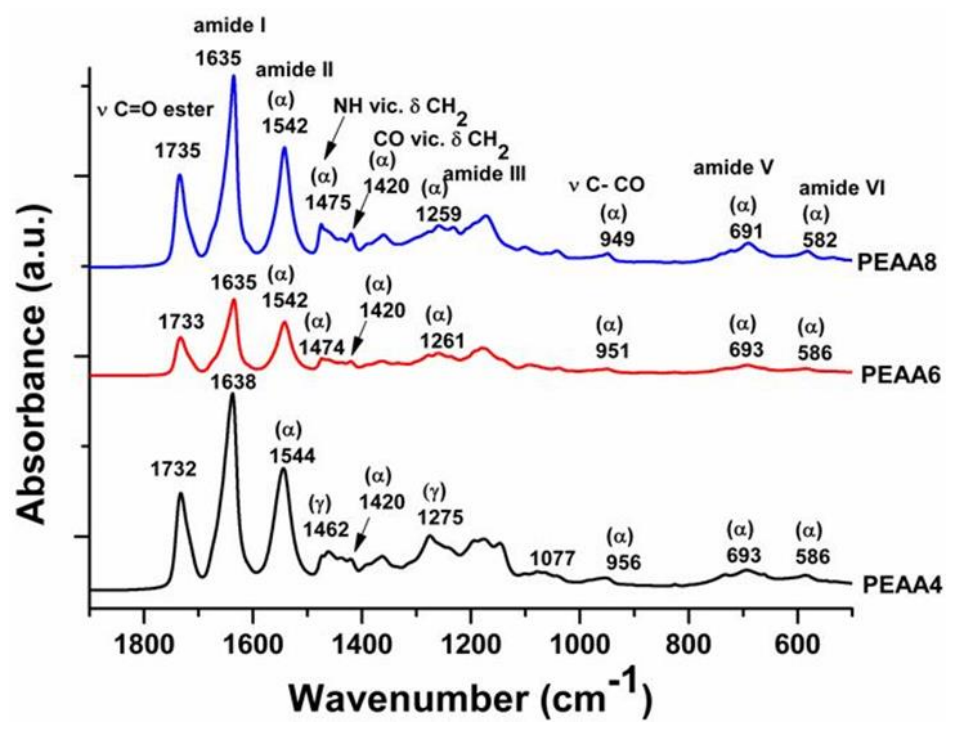


Figure 2: FT-IR spectra of the PEAA series for the wave number region (a) $3600-1800 \mathrm{~cm}^{-1}$ and (b) $1800-600 \mathrm{~cm}^{-1}$ measured at room temperature

Table 3: Assignment of FT-IR characteristic peaks in the synthesized PEAAs and their comparison with the ones of nylon 6

\begin{tabular}{|c|c|c|c|c|c|}
\hline Assignment $^{\mathbf{a}}$ & Nylon6 $(\alpha)$ & Nylon $6(\gamma)$ & PEAA4 & PEAA6 & PEAA8 \\
\hline v NH H-bonded & & & 3301 & 3302 & 3303 \\
\hline $\mathbf{v a}$ & & & 2941 & 2938 & 2935 \\
\hline $\mathbf{v}_{\mathrm{s}}$ & & & 2866 & 2863 & 2857 \\
\hline Amide I & & & 1638 & 1635 & 1635 \\
\hline Amide II & $\sim 1540$ & $\sim 1560$ & $1544(\alpha)$ & $1542(\alpha)$ & $1542(\alpha)$ \\
\hline $\mathrm{NH}$ vic. $\mathrm{CH}_{2}$ bend & $\sim 1475$ & & & $1474(\alpha)$ & $1475(\alpha)$ \\
\hline $\mathrm{CH}_{2}$ bend & 1464 & 1463 & $1462(\gamma)$ & & \\
\hline $\mathrm{CO}$ vic. $\mathrm{CH}_{2}$ bend & 1417 & & $1420(\alpha)$ & $1420(\alpha)$ & $1420(\alpha)$ \\
\hline Amide III & 1265 & 1269 & $1275(\gamma)$ & $1261(\alpha)$ & $1259(\alpha)$ \\
\hline v C-CO & 959 & 977 & $956(\alpha)$ & $951(\alpha)$ & $949(\alpha)$ \\
\hline Amide V & 691 & 712 & $693(\alpha)$ & $693(\alpha)$ & $691(\alpha)$ \\
\hline Amide VI & 579 & 623 & $586(\alpha)$ & $586(\alpha)$ ho & $582(\alpha)$ \\
\hline
\end{tabular}

${ }^{a} v$ : stretching mode

The thermal stability of PEAAs was investigated with the help of TGA under nitrogen atmosphere. As can be seen from Table 4, the PEAAs are stable up to $350^{\circ} \mathrm{C}$. The TGA curves reveal similar single stage degradation for all studied polymers (cf. Figure 3). The high thermal stability allows processing them in the melt. The thermal behavior of the synthesized PEAAs was analyzed by the DSC technique. To this end, the thermal history of the samples was erased during the first heating. The DSC traces corresponding to the cooling and the second heating are presented in Figure 4. One can see that the crystallization temperature $\left(\mathrm{T}_{\mathrm{c}}\right)$ of PEAA4 and PEAA6 is 141 and $143{ }^{\circ} \mathrm{C}$, respectively (cf. Figure $4 \mathrm{a})$. Although their $\mathrm{T}_{\mathrm{c}}$ 's are similar, the enthalpy of crystallization $\left(\Delta \mathrm{H}_{\mathrm{c}}\right)$ for the latter sample is much higher. For PEAA8 a further increase of $\Delta \mathrm{H}_{\mathrm{c}}$ and decrease of $\mathrm{T}_{\mathrm{c}}$ was detected (Table 4). It is reasonable to assume that 
crystallinity of the samples enhances with the increase of the alkylene chain length of the dicarboxylic esters because of increased chain flexibility. The second heating curves show a single melting peak for all samples with close melting temperature values $\mathrm{T}_{\mathrm{m}}$ in the range of $134-137^{\circ} \mathrm{C}$ (cf. Figure $4 \mathrm{~b}$ ). On the other hand, in line with the previously mentioned values of $\Delta \mathrm{H}_{\mathrm{c}}$ the enthalpy of melting $\left(\Delta \mathrm{H}_{\mathrm{m}}\right)$ significantly increases from PEAA4 to PEAA8. This observation further confirms that the longer flexible alkylene spacer results in formation of better quality crystals. It is interesting to note that in the region of $80-90{ }^{\circ} \mathrm{C}$ a weak endothermic peak can be observed on the heating scans, and it is mostly pronounced for PEAA8. This peak can possibly be attributed to crystal phase reorganization on heating, which is a typical observation for the family of semirigid-chain semicrystalline polymers.[33-34] A detailed analysis of the semicrystalline structure was performed by X-ray scattering technique.

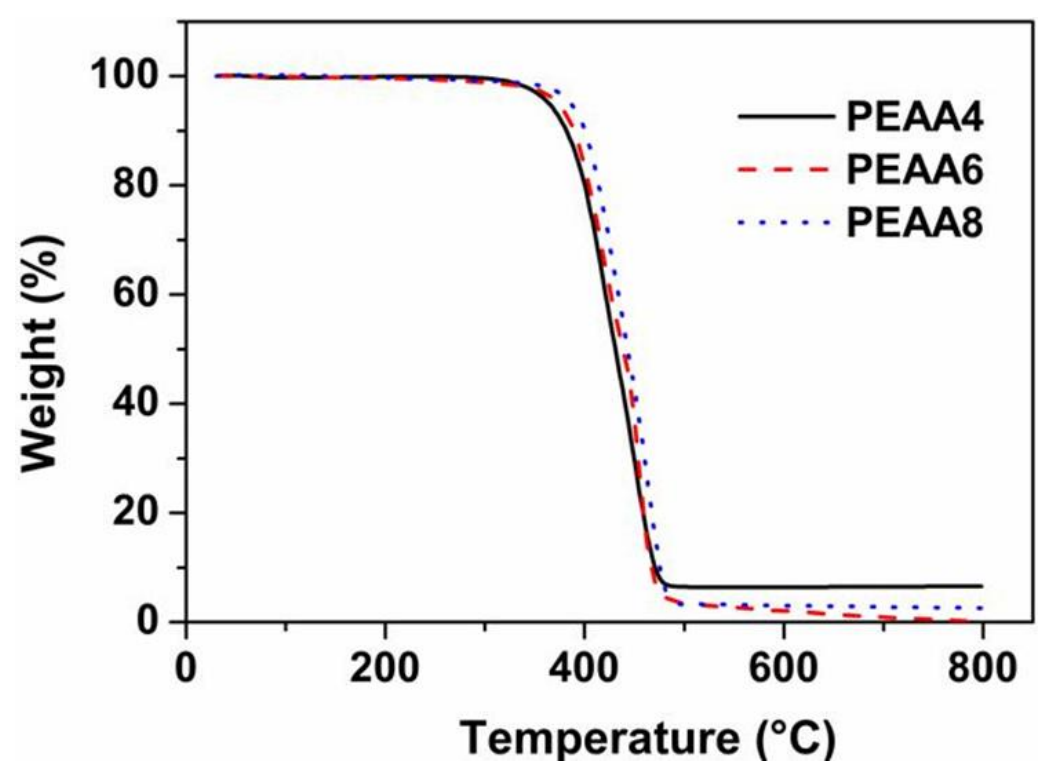

Figure 3: TGA thermograms of the studied polymers.

(a)

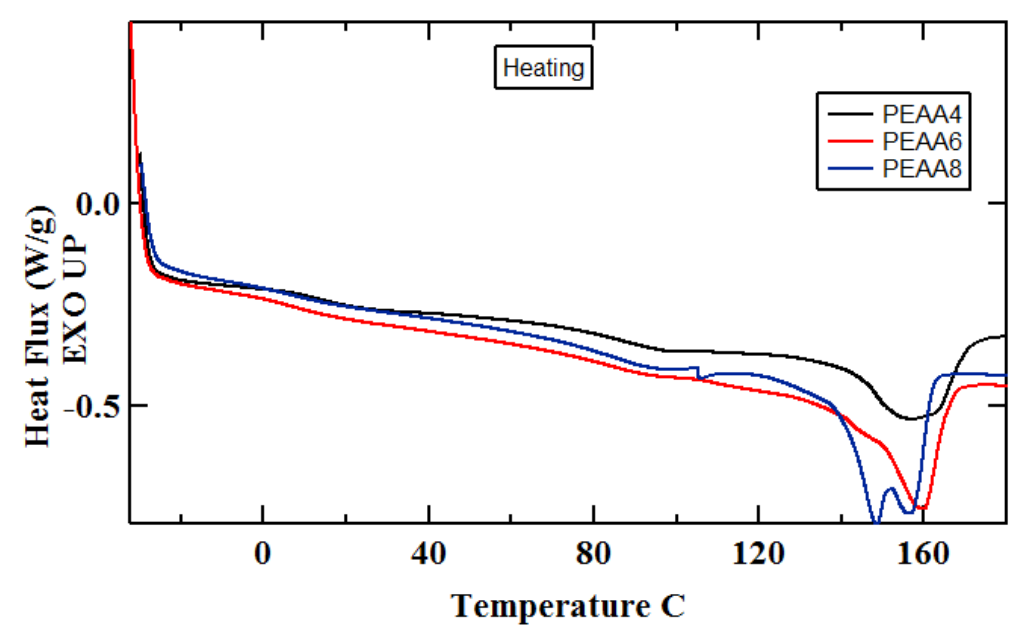


(b)

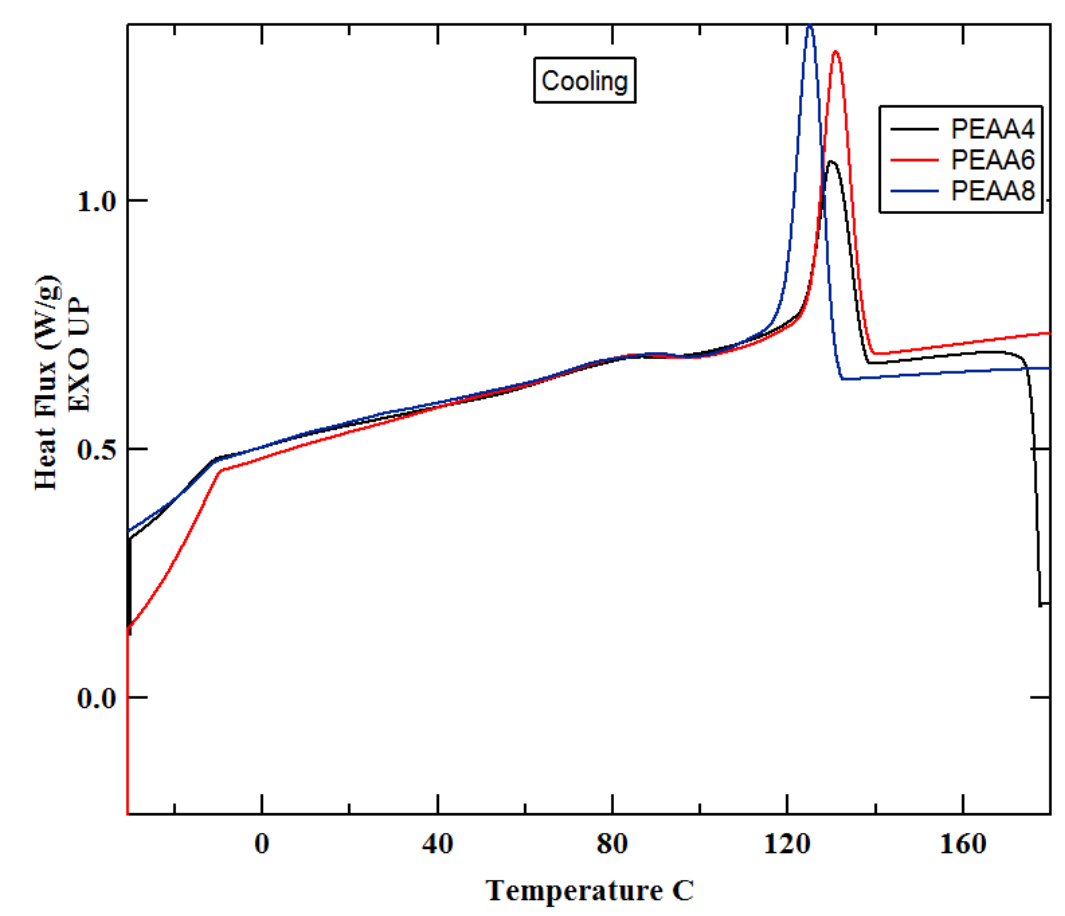

Figure 4: DSC of PEAA4, PEAA6 and PEAA8: (a) cooling scan and (b) second heating scan (performed at a heating and cooling rate of $10 \mathrm{~K} / \mathrm{min}$ ).

Table 4: Thermal properties of the synthesized PEAAs.

\begin{tabular}{|c|c|c|c|c|c|c|c|}
\hline Polymer & $\begin{array}{l}\mathbf{T}_{\mathbf{d}}{ }^{(\mathbf{a})} \\
\left({ }^{\circ} \mathbf{C}\right)\end{array}$ & $\begin{array}{l}\mathbf{T}_{\mathbf{g}}{ }^{(\mathbf{b})} \\
\left({ }^{\circ} \mathbf{C}\right)\end{array}$ & $\begin{array}{l}\mathbf{T}_{\mathbf{m} \mathbf{1}}(\mathbf{b}) \\
\left({ }^{\circ} \mathbf{C}\right)\end{array}$ & $\begin{array}{l}\mathbf{T}_{\mathbf{m} 2}{ }^{(\mathbf{b})} \\
\left({ }^{\circ} \mathbf{C}\right)\end{array}$ & $\begin{array}{l}\Delta \mathbf{H}_{\mathrm{m}}{ }^{(\mathbf{b})} \\
(\mathrm{J} / \mathbf{g})\end{array}$ & $\begin{array}{l}\mathbf{T}_{\mathbf{c}}^{(\mathbf{b})} \\
\left({ }^{\circ} \mathbf{C}\right)\end{array}$ & $\begin{array}{l}\Delta \mathbf{H}_{\mathbf{c}}{ }^{(\mathbf{b})} \\
(\mathrm{J} / \mathrm{g})\end{array}$ \\
\hline PEAA4 & 385 & 6.8 & 138.97 & 159.97 & 28.2 & 137.2 & 21.86 \\
\hline PEAA6 & 412 & 7.82 & 135.99 & 152.88 & 34.89 & 138.31 & 32.73 \\
\hline PEAA8 & 405 & 4.19 & 136.91 & 151.95 & 39.87 & 131.7 & 35.10 \\
\hline
\end{tabular}

The SAXS curves of the synthesized PEAAs measured at room temperature are displayed in Figure 5. All curves reveal a broad small-angle maximum in the region from 0.006 to $0.03 \AA^{-1}$. This maximum can be attributed to the characteristic interference peak from the crystalline lamellar stack with the long period of 65,74 and $81 \AA$ for PEAA4, PEAA6 and PEAA8, respectively. The increase of the long period is related to increase of the alkylene spacer length and therefore of the corresponding length of the crystallizable fragment. Two wide-angle reflections were identified as the fourth and sixth orders of the main SAXS peak ( $c f$. Table 5), similarly to those found earlier by Lotz and coauthors for a poly(ester amide).[35] 


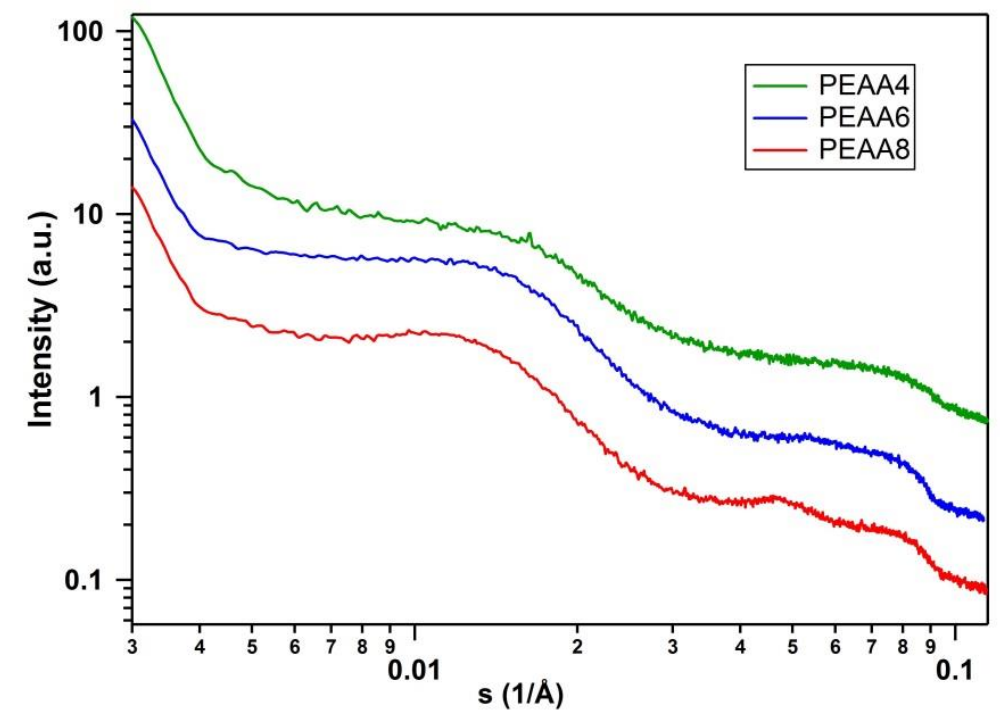

Figure 5: SAXS curves of PEEA samples measured at room temperature.

Table 5: The d-spacings (in A) calculated from SAXS and WAXS patterns of the PEAA samples.

\begin{tabular}{lccc}
\hline & PEAA4 & PEAA6 & PEAA8 \\
\hline 1st order & 65 & 74 & 81 \\
4th order & 18.1 & 18.7 & 20.4 \\
6th order & 11.6 & 12.7 & 13.1 \\
8th order & 8.6 & 9.1 & - \\
10 th order & 6.4 & - & - \\
120 & 4.26 & & 4.40 \\
060 & 3.85 & 4.34 & 3.88 \\
140 & - & 3.71 & - \\
\hline
\end{tabular}

An additional piece of information on the semicrystalline structure was extracted from the WAXS curves (cf. Figure 6). In the range 0.07-0.18 $\AA^{-1}$ a series of broad maxima can be observed which were indexed as higher orders of the fundamental SAXS peak mentioned above (see Table 5). Interestingly, the peaks are better pronounced for the PEAA4 sample indicating sharper electron density contrast along the polymer chain. In contrast, for PEAA8 only the sixth 
order of the main peak was detected on the WAXS curve that may point on the presence of conformational defects in the main chain. The clear dependence of the long period on the alkyl spacer length of the PEAAs and observation of many orders of the main SAXS interference peak prompts suggesting that the crystals are built by the polymer chains in the extended-chain conformation. As far as the wide-angle peaks are concerned, i.e., the ones located in the range of $0.18-0.28 \AA^{-1}$, two relatively narrow peaks are observed for the PEAA6 and PEAA8 samples. According to previous works, the peaks are attributed to the inter-chain distances in the orthorhombic unit cell [35]. The peaks' indexation is presented in Table 5. The $a$ and $b$ parameters computed in the hypothesis of the orthorhombic unit cells are given in Table 6. It is noteworthy that the c-parameter obviously cannot be estimated from the d-spacings of the only observed hk0 reflections. One can see that the lateral unit cell parameters are closed for all the polymers. A somewhat different $a$-parameter for the PEAA4 sample can be explained by broadening of the WAXS peaks, which is probably caused by a smaller crystal size in the direction normal to the chain axis.

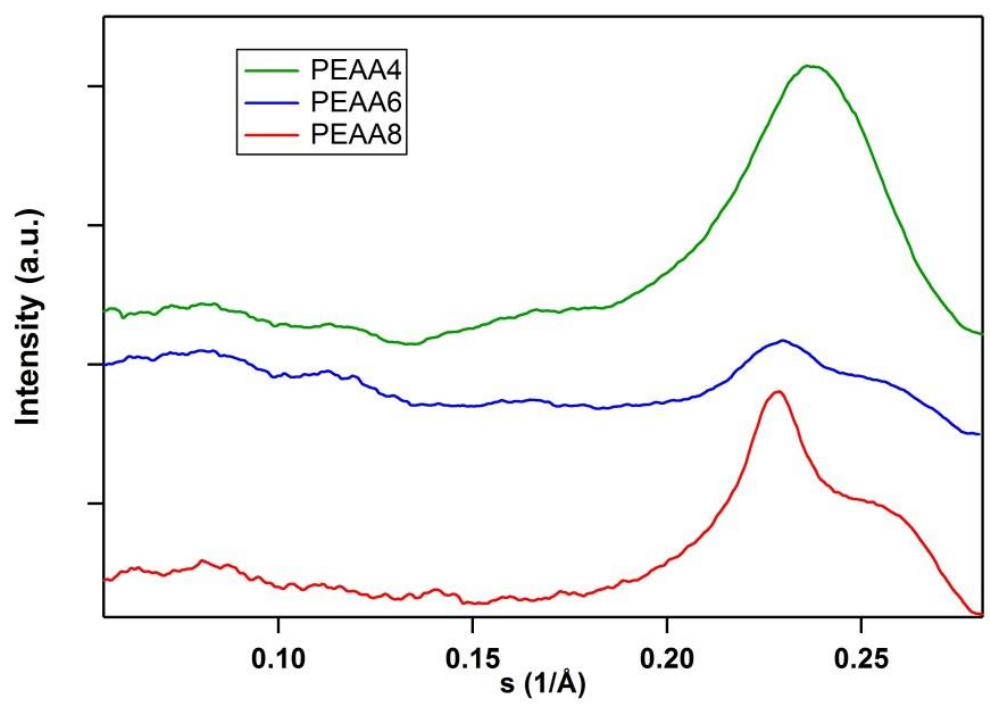

Figure 6: WAXS curves of PEAA samples measured at room temperature.

Table 6: Unit cell parameters calculated from the WAXS measurements.

\begin{tabular}{lccc}
\hline & PEAA4 & PEAA6 & PEAA8 \\
\hline & & & 4.75 \\
$\mathrm{a}, \AA$ & 4.59 & 4.72 & 23.30 \\
$\mathrm{~b}, \AA$ & 23.26 & 23.31 & 2 \\
\hline
\end{tabular}

\section{Conclusions}

Poly(ester amide amide)s (PEAAs) of high molecular weight have been synthesized via a two-step melt polycondensation technique from preformed $\alpha, \omega$-aminoalcohols containing an amide group and dicarboxylic methyl esters of varying alkylene chain lengths. All the polymers exhibit a melt transition at around $135^{\circ} \mathrm{C}$ and thermal degradation above $350^{\circ} \mathrm{C}$. As shown from the DSC data, the crystallization rate decreases but the crystallinity increases with the increase of the alkylene chain length of the dicarboxylic acid methyl ester used in the polycondensation. Both 
DSC and TGA data testify that the synthesized PEAAs can be further melt processed without degradation as the decomposition temperatures of these PEAAs are significantly higher than their melting temperatures. X-ray scattering experiments in small and wide angles reveal formation of crystals with extended-chain conformation resulting in strict periodicity of electron density along the main chain. The chain packing in the direction normal to the chain axis is similar for all the studied PEAAs. One can speculate that the crystal structure is formed by regular hydrogen bonding network typical of polyamides. The obtained characteristics of the newly synthesized PEAAs can open new perspectives for fabrication of films, highly oriented fibers and injection-molded parts with good thermal stability and mechanical performance.

Acknowledgments: The authors acknowledge the Ministry of Education and Science of the Russian Federation for financial support (contract No. 14.578.21.0190 (RFMEFI57816X0190))

\section{References}

1. Kaplan DL, Thomas E, Ching C (1993) Biodegradable Materials and Packaging. Technomic Press: Lancaster, PA.

2. Moore GF, Saunders SM (1997) Advances in Biodegradable Polymers. Rapra Review Reports: 9/2. Rapra Technology Limited: Shropshire.

3. Gonsalves KE, Chen X, Cameron JA (1992) Degradation of nonalternating poly(ester amides). Macromolecules 25:3309-3312.

4. Wiegand S, Steffen M, Steger R, Koch RJ (1999) Isolation and Identification of Microorganisms Able to Grow on the Polyester Amide BAK. J Envir Pol Degrad 7:145-156.

5. Lee S, Park JW, Yoo YT, Im SS (2002) Hydrolytic degradation behaviour and microstructural changes of poly(ester-co-amide)s. Polym Degrad Stabil 78:63-71.

6. Qian ZY, Li S, Hailian Z, Xiaobo L (2003) Synthesis and thermal degradation of biodegradable polyesteramide based on $\varepsilon$-caprolactone and 11-aminoundecanoic acid. Polym Degrad Stabil 81:279-286.

7. Qian ZY, Sai L, He Y, Li C, Liu X (2003).Synthesis, characterization and in vitro degradation of biodegradable polyesteramide based on lactic acid. Colloid Pol Sci 281:869-875.

8. Alla A, Rodrigez-Galan A, Martinez-de-llarduya A, Munoz-Guerra S (1997) Degradable poly(ester amide)s based on 1-tartaric acid. Polymer 38:4935-4944.

9. Botines E, Rodrigez-Galan A, Puiggali J (2002) Poly(ester amide)s derived from 1,4-butanediol, adipic acid and 1,6-aminohexanoic acid: characterization and degradation studies. Polymer 43:6073-6084.

10. Ferre T, Franco L, Rodrigez-Galan A, Puiggali J (2003) Poly(ester amide)s derived from 1,4-butanediol, adipic acid and 6-aminohexanoic acid. Part II: composition changes and fillers. Polymer 44:6139-6152.

11. Armelin E, Paracuellos N, Rodrigez-Galan A, Puiggali J (2001).Study on the degradability of poly(ester amide)s derived from the $\alpha$-amino acids glycine, and 1-alanine containing a variable amide/ester ratio. Polymer 42:79237932.

12. Kawasaki N, Nakayama A, Maeda Y, Hayashi K, Yamamoto N, Aiba S (1998). Synthesis of a new biodegradable copolyesteramide: poly(L-lactic acid-co- $\varepsilon$-caprolactam). Macromol Chem Phys 199:2445-2451.

13. Perez-Rodriguez A, Alla A, Fernandez-Santin JM, Munoz-Guerra S (2000).Poly(ester amide)s derived from tartaric and succinic acids: Changes in structure and properties upon hydrolytic degradation. J Appl Polym Sci 78:486-494. 
14. Andini S, Ferrara L, Maglio G, Palumbo R (1988) Synthesis of block polyesteramides containing biodegradable poly(L,L-lactide) segments. Macromol Chem Rapid Commun 9:119-124.

15. Castaldo L, de Candia F, Maglio G, Palumbo R, Strazza G (1982) Synthesis and physico-mechanical properties of aliphatic polyesteramides. J Appl Polym Sci 27:1809.

16. Castaldo L, Maglio G, Palumbo R, (1992).Synthesis and preliminary characterization of polyesteramides containing enzymatically degradable amide bonds Polym Bull 28:301-307.

17. Pivsa-Art S, Nakayama A, Kawasaki N, Yamamoto N, Aiba S (2002) Biodegradability study of copolyesteramides based on diacid chlorides, diamines, and diols. J Appl Polym Sci 27:774-784.

18. Bera S, Jedlinski Z (1992) Block/segmented polymer: 2. Studies on the thermal and mechanical properties of poly(amide ester)-ester copolymer. Polymer 33:4331-4336.

19. Bera S, Jedlinski Z (1993) Block/segmented polymers. A new method of synthesis of copoly(amide-ester)-ester polymer J Polym Sci A: Polym Chem 31:731-739.

20. Stapert HR, Dijkstra PJ, Feijen J (1998) Synthesis and characterization of aliphatic poly(esteramide)s containing symmetrical bisamide blocks. Macromol Symp 130:91-102.

21. Dijkstra PJ, Stapert HR, Feijen J (2000) Synthesis of aliphatic poly(ester-amide)s containing uniform bisamidebisester blocks. Macromol Symp 152:127-137.

22. Lips PAM, Broos R, van-Heeringen MJM, Dijkstra PJ, Feijen J (2005) Synthesis and characterization of poly(ester amide)s containing crystallizable amide segment Polymer 46:7823-7833.

23. Garg P, Keul H, Klee D, Möller M (2009) Thermal Properties of Poly(ester amide)s with Isolated, Two Adjacent and Three Adjacent Amide Groups within a Polyester Chain. Macromol. Chem. Phys. 20:1754-1765.

24. Holden G, Legge NR, Quirk R, Schroeder MJM (1996) Thermoplastic elastomers. New York: Hanser.

25. Odarchenko Y, Doblas D, Rosenthal M, Broos R, Hernandez J, Soloviev M, Anokhin DV, Vidal L, Feijen, J, Sijbrandi N, Mes E, Kimenai A, Bar G, Dijkstra P, Ivanov, DA (2014) Primary chemical sequence ultimately determines crystal thickness in segmented all-aliphatic co-polymers. Macromolecules 47 (22):7890-7899.

26. Odarchenko YaI, Sijbrandi NJ, Rosenthal M, Kimenai AJ, Mes EPC, Broos R, Bar G, Dijkstra PJ, Feijen J, Ivanov DA (2013) Structure formation and hydrogen bonding in all-aliphatic segmented copolymers with uniform hard segments. Acta Biomaterialia 9:6143-6149.

27. Sijbrandi NJ, Kimenai AJ, Mes EPC, Broos R, Bar G, Rosenthal M, Odarchenko YI, Ivanov DA, Dijkstra PJ, Feijen J (2012) Synthesis, morphology and properties of segmented poly(ether ester amide)s comprising uniform glycine or $\beta$-alanine extended bisoxalamide hard segments. Polymer 53:4033-4044.

28. Sijbrandi NJ, Kimenai AJ, Mes EPC, Broos R, Bar G, Rosenthal M, Odarchenko Y, Ivanov DA, Dijkstra PJ, Feijen J (2012) Synthesis, morphology and properties of segmented poly(ether amide)s with uniform oxalamide based hard segments. Macromolecules 45:3948-3961.

29. Okada M (2002) Chemical syntheses of biodegradable polymers. Prog Polym Sci 27:87-133.

30. Stapert HR, Bouwen AM, Dijkstra PJ, Feijen J (1999) Environmentally degradable aliphatic poly(ester-amide)s based on short, symmetrical and uniform bisamide-diol blocks, 1. Synthesis and interchange reactions. Macromol. Chem. Phys. 200:1921-1929.

31. Garg P, Keul H, Klee D, Möller M (2009) Concept and Synthesis of Poly(ester amide)s with One Isolated, Two or Three Consecutive Amide Bonds Randomly Distributed Along the Polyester Backbone. Des Monomers Polym 12:405-424.

32. Kohan MI (1995) Nylon Plastics Handbook. Hanser Publishers: Munich. 
33. Melnikov AP, Rosenthal M, Rodygin AI, Doblas D, Anokhin DV, Burghammer M, Ivanov DA (2016) Reexploring the Double-Melting Behavior of Semirigid-Chain Polymers with an in-situ Combination of Synchrotron Nano-Focus X-ray Scattering and Nanocalorimetry. European Polymer Journal 81:598-606.

34. Ivanov DA, Jonas AM, Legras R (2000) The crystallization of poly(aryl-ether-ether-ketone) (PEEK). Reorganization processes during gradual reheating of cold-crystallized samples. Polymer 41:3719-3727.

35. Paredes N, Casas MT, Puiggali J, Lotz B (1999) Structural Data on the Packing of Poly(ester amide)s Derived from Glycine, Hexanediol, and Odd-Numbered Dicarboxylic Acids J Polym Sci B: Polym Phys 37:25212533.

\section{Solubility}

The solubility of PEAA's in differents solvents was invertigate in this study. It was observe by putting a small part of material solvent. It was sow that Formic acid disolve immediately the materials, Acid Hydrocloric and phenol had solve all materials in $20 \mathrm{~min}$. The trofluoroacetic acid had solve the PEAA8 in somme second, PEAA6 in 30min and finaly the PEAA4 in $1 \mathrm{H}$. For oll solvant it was show that the PEAA8 is most easbly sovable, this is may due to the chains whitch is the longest and the most easaly cut.

\begin{tabular}{|l|l|}
\hline Solvent & solubility \\
\hline Formic acid & Yes \\
\hline Hydrochloric acid & Yes \\
\hline Phenol & Yes \\
\hline Trifluoroacetique Acide & Yes \\
\hline Dimethylformamide & No \\
\hline Ethanol & Yes (hot) \\
\hline Tetrahydrofuran & No \\
\hline
\end{tabular}

